\title{
Development of an Extra-vehicular (EVA) Infrared (IR) Camera Inspection System
}

\author{
Michael Gazarik, Dave Johnson, Ed Kist, Frank Novak, Charles Antill, David Haakenson, Patricia Howell, \\ John Pandolf, Rusty Jenkins, NASA Langley Research Center. \\ Rusty Yates, Ryan Stephan, NASA Johnson Space Center \\ Doug Hawk, Swales Aerospace Corporation, NASA Goddard Space Flight Center \\ Michael Amoroso, Jacobs-Sverdrup, NASA Johnson Space Center
}

\begin{abstract}
Designed to fulfill a critical inspection need for the Space Shuttle Program, the EVA IR Camera System can detect crack and subsurface defects in the Reinforced Carbon-Carbon (RCC) sections of the Space Shuttle's Thermal Protection System (TPS). The EVA IR Camera performs this detection by taking advantage of the natural thermal gradients induced in the RCC by solar flux and thermal emission from the Earth.

This instrument is a compact, low-mass, low-power solution $(1.2 \mathrm{~cm} 3,1.5 \mathrm{~kg}, 5.0 \mathrm{~W})$ for TPS inspection that exceeds existing requirements for feature detection. Taking advantage of ground-based IR thermography techniques, the EVA IR Camera System provides the Space Shuttle program with a solution that can be accommodated by the existing inspection system. The EVA IR Camera System augments the visible and laser inspection systems and finds cracks and subsurface damage that is not measurable by the other sensors, and thus fills a critical gap in the Space Shuttle's inspection needs.

This paper discusses the on-orbit RCC inspection measurement concept and requirements, and then presents a detailed description of the EVA IR Camera System design.
\end{abstract}

\section{INTRODUCTION}

During Space Shuttle Columbia's last mission in 2003, ground video imagery indicated that insulating foam fell from the External Tank left bipod ramp during ascent and struck Columbia under its left wing. A Debris Assessment Team (DAT) was formed to study the strike. Unfortunately, the DAT did not have sufficient imagery and analysis tools with which to assess the severity of the strike, and the Mission Management Team (MMT) decided to postpone further assessment until after landing.

Following the accident, the Columbia Accident Investigation Board (CAIB) concluded that the foam struck the left wing leading edge of Columbia near reinforced carbon-carbon (RCC) panel 8, and that the resultant RCC damage provided a path for superheated air to penetrate the wing during reentry. The superheated air melted the aluminum structure within the wing, and Columbia disintegrated over Texas.

The CAIB made a series of recommendations to NASA that are intended to prevent future such accidents. Recommendation 6.4-1 calls for NASA to develop a comprehensive tile and RCC inspection and repair capability. NASA responded to this recommendation by implementing a suite of on-orbit inspection tools that are capable of detecting most critical RCC damage. The first line of inspection is the Orbiter Boom Sensor System (OBSS) which includes one video camera and two lasers mounted on the end of a long boom. The OBSS is programmed to scan all RCC surfaces during flight in order to initially detect any RCC damage.

If any damage is detected by the OBSS scan, a crewmember will conduct an extravehicular activity (EVA) to perform a more detailed inspection of the damage site. During this detailed inspection, the crewmember will employ two additional inspection tools: the EVA Digital Camera and the EVA IR Camera. The EVA Digital Camera is needed to acquire high-resolution visible imagery of the surface RCC damage, and EVA IR Camera is needed to determine the extent of subsurface RCC damage.

The data collected during the detailed inspection will enable the MMT to decide whether to fly "as is", repair the damage, or take safe haven on the International Space Station (ISS). Also, if a repair is required, the detailed inspection will help the MMT decide how to make the repair. For example, a small crack with 
little underlying damage may only require a filler repair, while a small crack with much underlying damage may require a patch repair.

Although the Columbia accident occurred in February, 2003, the need for an EVA IR Camera to detect underlying RCC damage was not recognized by the Space Shuttle Program (SSP) until November, 2004. At that time, the project team laid out an aggressive schedule to deliver a camera system for flight by STS115 (the third flight back), and the SSP strongly encouraged the team to deliver the camera system by STS121 (the second flight back). In the end, the team delivered the camera system for STS-114 (the first flight back); an EVA IR Camera was launched in July, 2005, aboard the Shuttle Discovery, and it is presently on ISS.

In addition to schedule constraints, the EVA IR Camera development had technology, operational, and funding constraints. In order to detect underlying RCC damage with infrared thermography, a thermal gradient through the RCC panel must be created. On the ground, inspectors use large flash lamps to create the thermal gradient. However, packaging a flash lamp for space is impractical, because it is bulky. Also, high voltages within the lamp may pose a safety risk.

Rather than packaging a flash lamp for space, the EVA IR Camera project team conducted a series of tests on the ground to demonstrate that sunlight and shadowing could be used to create an adequate thermal gradient through the RCC panels. This greatly simplifies the development task and helps control project costs. However, it also increases operational complexity, because crewmembers are constrained to inspecting the RCC in sunlight.

Given the urgency with which the program needed to have use of the EVA IR Camera for RCC inspection together with the immaturity of using infrared thermography in space for RCC damage detection, the SSP directed the project to limit its initial scope to building flight units certified as safe to test the application of infrared thermography for on-orbit RCC inspection rather than to building flight units certified to detect specific RCC damage.

The SSP plans to conduct two flight tests with the EVA IR Camera: one on STS-121, and another on STS115. During these tests, crewmembers will image the vehicle wing leading edges to validate ground thermal models, and crewmembers will image RCC samples with known damage to compare with ground test results. Together, these flight test data may later be used as part of an effort to certify that the EVA IR Camera can detect specific RCC damage.

The SSP established a budget of \$6.4M for development of the EVA IR Camera system and completion of the two flight tests. The EVA IR Camera system development is completed, and uncharacteristic of most space flight projects, the project is on budget. The team attributes the success of completing the system development ahead of schedule and on budget largely to having consistent customer advocacy, prototyping the system, getting early user feedback, having skilled key personnel, and having great teamwork.

\section{SYSTEM REQUIREMENTS}

To convert a Commercial-Off-The-Shelf (COTS) camera into an instrument that could be used on board the Space Shuttle and International Space Station (ISS) a System Requirements Document was written to direct the build process.

The requirements can be broken into two major categories. The first requirements were those dictated by the measurement itself. That is, the functions we were required to build into the camera so that it could perform thermography on the RCC panels. These requirements were written by the EVA IR Camera Project personnel.

The second group of requirements dictated crew and vehicle safety. The EVA IR Camera was designated a Demonstration Technology Objective (DTO) and used the Johnson Spaceflight Center identified JSC 28484: Program Requirements Document for JSC Non-Critical Government Furnished Equipment and JSC 26626: Extra-Vehicular Activities (EVA) Generic Design Requirements Document as the parent documents for this mission. There are 68 additional documents that are referenced in the parent documents that shaped the design of the camera. To guarantee the highest quality product, in cases where similar requirements were cited in the Reference Documents, the more stringent requirement was selected.

The following requirements were addressed in the System Requirements Document:

- Functional Requirements

- Non-Functional Requirements 
- External Interface Requirements

- General Design and Construction Requirements

- Structural Design Requirements

- $\quad$ Electrical Design Requirements

- Soft Goods Design Requirements

- Human Factors Design Requirements

- Ground Support Equipment Requirements

- Customer Imposed Verification Requirements

In all, there were 275 individual requirements written to direct the design and build of this camera. For every requirement, a verification method was written to insure compliance. Verification could be in the form of testing, similarity, or inspection and were written into a Verification and Validation Matrix.

After the Requirements document and the Verification and Validation Matrix were completed, they went through a review process. Only after this review process was complete could the build begin.

\section{VERIFICATION AND VALIDATION PLAN}

Extravehicular Activity (EVA) Infrared (IR) Camera System successfully passed through an extensive Verification and Validation (V\&V) program to confirm that the EVA IR Camera, associated components and end items comply with specifications in the Systems Requirements, EIC 0002, and function properly as an integrated unit. Verification of the EVA IR Camera functional capabilities and subsystem performance was performed through analyses using non-real-time tools, tests using real-time test facilities, inspection as it applies to the manufacturing processes used in hardware fabrication and software generation, and assessment as it applies to human factors, maintainability, accessibility, and transportability of the system features.

\section{Environmental Testing Summary:}

The camera units were put through a rigorous environmental test program which included an extensive burn-in test, acceptance thermal vacuum test, acceptance vibration test, shock test, bench handling drop test, packaged drop test, qualification thermal vacuum test, and qualification vibration test, electromagnetic compatibility test, off-gassing testing. The following table indicates the testing performed on each camera system developed:

\begin{tabular}{|c|c|c|c|c|c|c|c|c|c|c|c|c|c|c|c|c|}
\hline \multicolumn{2}{|c|}{ HARDWARE DESCRIPTION } & \multicolumn{14}{|c|}{ TEST DESCRIPTION } & \multirow[b]{2}{*}{\begin{tabular}{|l}
\multicolumn{1}{c}{ COMMENTS } \\
\\
$\qquad \begin{array}{l}\text { C Test Completed } \\
\text { P Test In-Process } \\
\text { S Test Pending } \\
\text { K Kennedy } \\
\text { Note: } \\
\text { Blank cells indicate no test } \\
\text { planned or scheduled. }\end{array}$
\end{tabular}} \\
\hline 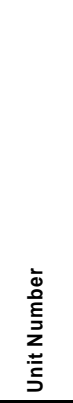 & Unit Description & 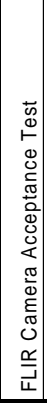 & 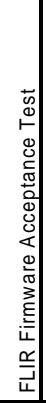 & 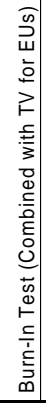 & 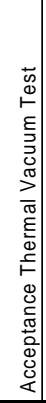 & 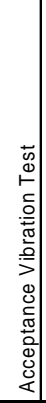 & $\begin{array}{l}\vec{s} \\
\stackrel{\circ}{ } \\
\stackrel{े}{0} \\
\stackrel{\circ}{\omega}\end{array}$ & 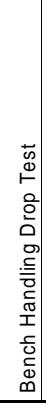 & 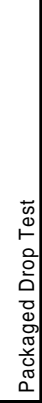 & 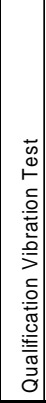 & 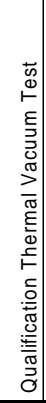 & $\underset{\sum}{\sum_{\Psi}^{U}}$ & 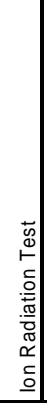 & 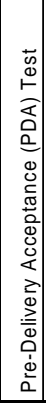 & 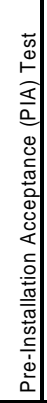 & \\
\hline E1 & Engineering/Training Unit & $\mathrm{C}$ & $\mathrm{C}$ & & C & & & & & & & $\mathrm{C}$ & & $\mathrm{C}$ & & Button enclosure outside chamber \\
\hline E2 & Engineering Unit & $\mathrm{C}$ & C & & & C & C & C & $\mathrm{C}$ & & & & C & $\mathrm{C}$ & & Two week return required after radiation tests \\
\hline F1 & Flight Unit (STS-114) & $\mathrm{C}$ & $\mathrm{C}$ & $\mathrm{C}$ & C & $\mathrm{C}$ & $\mathrm{C}$ & $\mathrm{C}$ & $\mathrm{C}$ & & & & & $\mathrm{C}$ & $\mathrm{K}$ & \\
\hline $\mathrm{F} 2$ & Flight Unit (STS-121) & $\mathrm{C}$ & $\mathrm{C}$ & $\mathrm{C}$ & $\mathrm{C}$ & $\mathrm{C}$ & $\mathrm{C}$ & $\mathrm{C}$ & $\mathrm{C}$ & & & & & $\mathrm{C}$ & $\mathrm{K}$ & \\
\hline F3 & Flight Unit (JSC Spare) & $\mathrm{C}$ & $\mathrm{C}$ & $\mathrm{S}$ & $\mathrm{S}$ & $\mathrm{S}$ & $\mathrm{S}$ & $\mathrm{S}$ & $\mathrm{S}$ & & & $\mathrm{C}$ & & $\mathrm{S}$ & $\mathrm{K}$ & \\
\hline $\mathrm{F} 4$ & Flight / Qual Unit & $\mathrm{C}$ & $\mathrm{C}$ & $\mathrm{C}$ & C & C & C & $\mathrm{C}$ & $\mathrm{C}$ & $\mathrm{C}$ & C & & & & & Qualification unit \\
\hline F6 & Flight Unit (ISS) & $\mathrm{C}$ & $\mathrm{C}$ & $\mathrm{S}$ & $\mathrm{S}$ & $\mathrm{S}$ & $\mathrm{S}$ & $\mathrm{S}$ & $\mathrm{S}$ & & & & & $\mathrm{S}$ & $\mathrm{K}$ & \\
\hline $\mathrm{F} 7$ & Flight Unit (LaRC Spare) & $\mathrm{C}$ & $\mathrm{C}$ & $\mathrm{S}$ & $\mathrm{S}$ & $\mathrm{S}$ & $\mathrm{S}$ & $\mathrm{S}$ & $\mathrm{S}$ & & & & & $\mathrm{S}$ & $\mathrm{K}$ & \\
\hline TA301 & Test Article & & & & & $\mathrm{C}$ & $\mathrm{C}$ & $\mathrm{C}$ & $\mathrm{C}$ & & & & & $\mathrm{C}$ & & \\
\hline TA303 & Test Article I Qual Unit & & & & & $\mathrm{C}$ & $\mathrm{C}$ & $\mathrm{C}$ & $\mathrm{C}$ & $\mathrm{C}$ & & & & $\mathrm{C}$ & & \\
\hline
\end{tabular}

A short description of selected environment test performed is provided in the following sections: 


\section{ION Radiation Testing}

Elements of the EVA Infrared Camera were tested at the Indiana University Cyclotron Facility (IUCF) to assess their susceptibility to high-energy ionizing radiation. All testing was done with proton beam energy of 200 Mega-electron Volts (MeV). The normal beam diameter of approximately $6 \mathrm{~cm}$ was passed through various copper vignettes to adjust the size of the final beam allowed to radiate the test article.

\section{Power Cycle Burn-in}

Power Cycle Burn in test was completed at NASA Langley Research Center. The hot and cold operational temperature plateaus were determined using the manufacturers recommendations and were set at $-5^{\circ} \mathrm{C}$ and $40^{\circ} \mathrm{C}$. The non-operational temperature plateaus were also determined using the manufacturer's recommendations. However, because the camera system is turned off during this period, the temperature levels are much more extreme. The non-operational temperature levels during the burn in test were determined to be $-30^{\circ}$ and $60^{\circ} \mathrm{C}$. Five cycles, were completed during the burn-in test. These five cycles were followed by a 48 hour, continuous, operational steady state period at an ambient temperature of $40^{\circ} \mathrm{C}$.

\section{Thermal Vacuum Testing:}

The EVA-IR FM Camera systems was tested exposed to workmanship and qualification level thermal vacuum environment to ensure the systems can operate and perform for the intended STS Missions per NASA Specification Environmental Acceptance Testing per NASA-JSC-ST-T 0023, Revision C.

As part of this test, the EVAIR Camera Systems were also be subjected to temperature ranges between -5C to $+54 \mathrm{C}(+2 \mathrm{C}$ to $+58 \mathrm{C}$ for the RCU). This thermal cycle was conducted in a vacuum of $1 \times 10-5$ torr or less. Test was conducted continuously for 1.5 thermal vacuum cycles prior to and following the thermal vacuum tests a pre/post performance functional check of the test article shall be performed. The functional check is an operational check of the test article to verify that all of the electronic components associated with the camera are working correctly, and were not damaged as a result of the high loads from the shock test. Qualification thermal vacuum testing was performed in a similar manner except that the camera system was subjected to temperature ranges between $-15 \mathrm{C}$ to $+64 \mathrm{C}(-8 \mathrm{C}$ to $+68 \mathrm{C}$ for the RCU).

\section{Random Vibration}

The objective of the vibration test was to measure the dynamic response of the EVA-IR Camera Flight Unit when subjected to a base excitation corresponding to STS-114/121 launch environments. The measured response (acceleration) was used to determine the workmanship and design of the test article base input that replicates the launch environment of the STS-114/121 space flight vehicles.

For the random vibration testing, the camera system was subjected to a random load spectrum that was based on the launch environment of the Mid-deck Locker area of the STS-114/121 space flight vehicles. The random test spectrum was a 6.1 grms vibration test over a frequency range of 20 to $2000 \mathrm{~Hz}$. for one minute at full level. Prior to and following the random vibration tests a pre/post functional check was performed on the camera. The functional check is an operational check of the camera that verifies all of the electronic components associated with the camera were working correctly, and were not damaged as a result of the loads from the random vibration test. Qualification vibration testing was performed in a similar manner except that the random test spectrum was a 7.8 grms vibration test over a frequency range of 20 to $2000 \mathrm{~Hz}$. for one minute at full level.

\section{EMC Testing}

The EVA-IR Camera was required to be compatible with both the Space Shuttle environment and the Space Station Environment. This limit, defined in SL-E-0002-Book 3, Volume 1, applies to external equipment. As per SL-E-0002-Book 3, Section 5.11.1 testing is required up to $1 \mathrm{GHz}$ or ten times the highest intentionally generated frequency within the EUT, whichever is greater. The highest intentionally generated frequency within the EVA-IR Camera is $48 \mathrm{MHz}$, generated in the base camera. Therefore, the radiated electric field emissions testing were required up to $1 \mathrm{GHz}$ to show compliance with SL-E-002Book 3, Volume 1. 


\section{ELECTRONIC SYSTEMS DEVELOPMENT}

In order to transform a Commercial, Off-The-Shelf (COTS) camera into a space flight qualified unit, several issues must be addressed.

- Can the camera electronics tolerate the on-orbit thermal conditions?

- Can the camera electronics operate and survive in a vacuum?

- Can the camera electronics tolerate the radiation environment?

- $\quad$ Can we use the vendor supplied batteries?

- Will there be corona issues due to high voltages?

- Will the outgassing of electrical components be within acceptable limits?

- Any unnecessary electronics functions adding mass and draining power?

The first and second concerns, operating at on-orbit thermal conditions and in a vacuum, were answered by testing the cameras in a thermal vacuum chamber. We found that the camera operated normally in a vacuum, but some of the integrated circuits ran too hot. To fix this problem, we formed copper heat straps and thermally bonded them to the integrated circuits (figure 1). The other end was bolted to the metal frame of the camera. We used thermal pads (Sil Pads) to fill gaps and maintain thermal conductivity where necessary. Additionally, to guard against the possibility of the camera getting colder than storage limits, survival heaters and thermostats were installed.
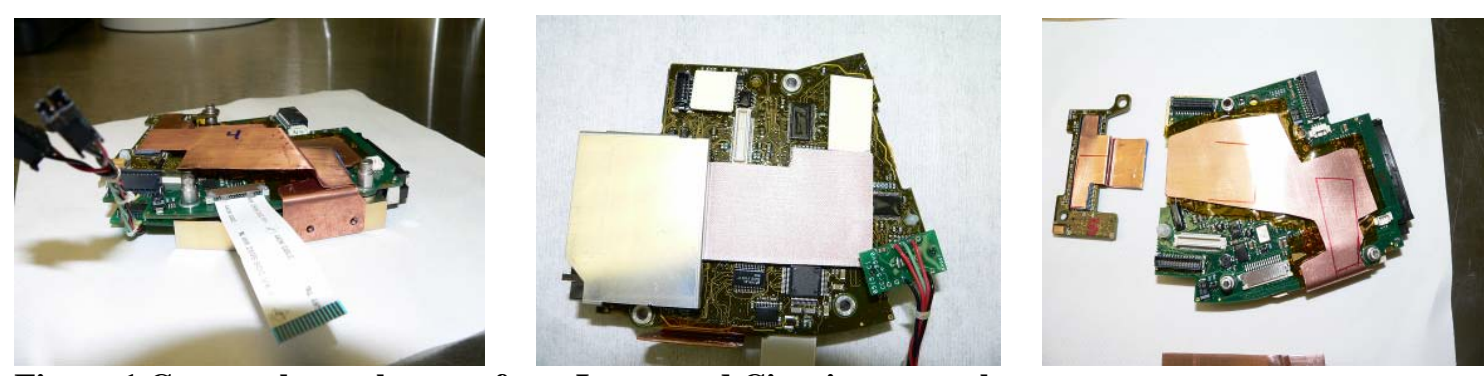

Figure 1 Copper thermal straps from Integrated Circuits to metal camera structure.

Radiation tolerance was tested using the cyclotron at Indiana University. This gave us insight into mean time between radiation upset events, and typical current profiles during single event upsets and latch-ups. The radiation tolerance of the COTS camera was deemed acceptable, but latch-up protection circuitry was designed and installed to provide an automatic power-down and reset functions in case of radiation induced failure on orbit.

Space flight qualification for batteries is a complex and time consuming exercise. Therefore, we decided to look for a pre-qualified battery to use in the camera. We found that the EHIP battery (figure 2) was the right form factor and had the right amount of energy storage. This is the battery used to power the headlights on the space suit helmets. The camera housing was adapted to accept the EHIP battery. The DC-DC converters were designed to convert the batteries 6 volts to 12 volts for camera use. A battery voltage monitor was designed to alert the astronauts when approximately $75 \%$ of the battery charge is depleted. 


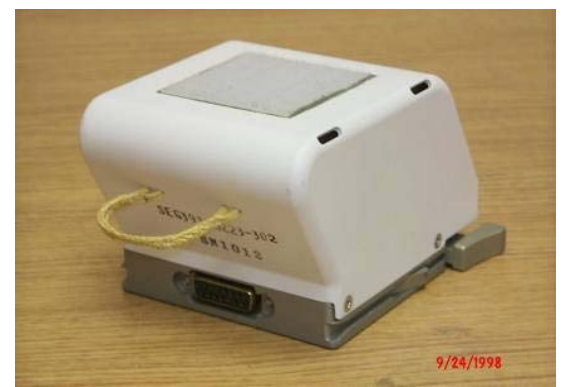

Figure 2. EHIP Battery

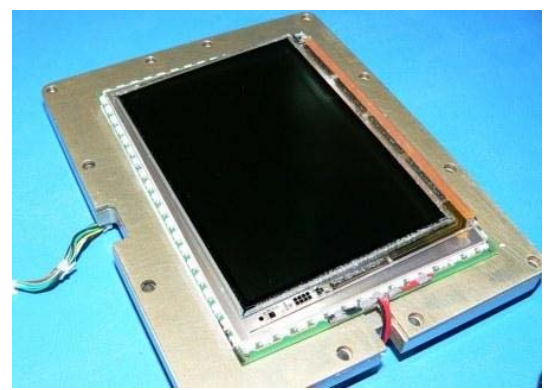

Figure 3. LED backlight replacing Fluorescent tube

During the vacuum testing it was discovered that the high voltage used for the cold cathode fluorescence (CCF) backlighting was generating a corona. It was decided that LCD displays CCF would be replaced with an array of white LEDs (figure 3). These LEDs were brighter than the CCF and would accommodate daylight viewing as well as eliminate the high voltage issue.

Outgassing was tested by placing the camera into a vacuum along with a witness plate. Contaminates condensed onto the witness plate and were analyzed for acceptability. Any issued identified were corrected.

In addition to structural modifications made to the camera, the visible camera (CCD) and eyepiece viewer were removed. The visible camera was not needed and added to mass and power consumption. The eyepiece couldn't be used with the spacesuit helmet and therefore was removed. A laser pointer supplied with the COTS camera was replaced by an eye safe laser that had been previously space qualified.

\section{THERMAL SYSTEM DEVELOPMENT}

The primary challenge for the thermal design of the EVA IR Camera is that the planned use for the instrument would occur in the harsh thermal environment of space. Not only does space introduce both extremely hot and cold environments, it is without the presence of air. The commercial-off-the-shelf units are, of course, thermally designed to operate in a standard pressure atmospheric environment. The air helps to cool the internal electronic components during camera operation by conduction and convection. Because the electronic components are designed to be thermally controlled using the ambient environmental temperature, they were not thermally coupled to the camera housing. In a vacuum environment, only radiation and conduction can be used to maintain the electronic components within the operating temperature range. As a result, 30 mil copper sheets were used to create a conductive path between the chips and the housing as shown in figure 1. Several thermal/vacuum tests were performed using the engineering unit to determine the thermal resistance between the camera housing and the internal electronic components. The primary requirement for the thermal control subsystem design states that:

\section{The IR Camera System shall operate throughout the hot and cold extreme environments as defined by the ISS EVA Thermal Environments Database.}

The ISS EVA Thermal Environments Database (IETED) is an exhaustive database that provides transient heat flux cubes for approximately 190 locations around the International Space Station (ISS) and Space Shuttle. The thermal subsystem for the IR camera was designed to ensure that the electronic components internal to the camera base unit (CBU) housing as well as the remote control unit (RCU) were maintained between the manufacturer's published temperature limits of $0^{\circ} \mathrm{C}$ to $70^{\circ} \mathrm{C}$. The $\mathrm{CBU}$ dissipates approximately 6.5 Watts during its operational mode. The RCU, on the other hand, dissipates 3.36 Watts. Therefore, the total power dissipation of the system is approximately 10 Watts during operation. The thermal design was completed to ensure that the electronic components internal to the camera system stay within the manufacturer's limit for the entire duration of an 8-hour EVA.

A hot and cold thermal analysis was performed for both the RCU and the CBU to ensure that these units would operate when exposed to the extreme thermal environments defined by the IETED. For each of these analyses, the camera system was assumed to be operating and the appropriate environmental heat fluxes were applied to the model. 
Both components of the EVA IR Camera system (RCU and CBU) were designed to be fabricated with 0.10 inch thick Aluminum Alloy 6061-T6. All of the radiator surfaces on the camera housing were assumed to be covered with 5 mil silver Teflon tape. Because the camera system is a handheld tool, it is impossible to ensure that the solar flux never impinges onto any given radiator surface. Because silver Teflon tape has a very low solar absorptivity, the solar load on the camera housing's radiator surface is reduced through the use of this coating. All of the remaining surfaces were assumed to be covered with 8-layer MLI. The outermost layer of the MLI for both units was assumed to be beta cloth. The beta cloth is added as an outer layer to the MLI to add ruggedness to the design.

As mentioned above, the extreme thermal environments that the camera could ever experience during an EVA were obtained using the IETED. Using the thermo-optical properties for the camera system, the database provided a six-sided flux cube that maximized the absorbed environmental load for the camera system's hot case and minimized the same for the camera system's cold case. The IETED includes the environmental heat flux loading due to solar heating as well as IR heating. The IR heating load is due to both the IR heating associated with the Earth as well as that attributed to the presence of ISS and the docked orbiter. The worst-case hot environmental, total (both IR and solar), incident (not absorbed), transient, heat flux profile for a single orbit is shown in figure 4. Figure 3 shows the worst-case cold environment for the EVA IR Camera system. It is important to note that these environments are not necessarily representative of the environments that are expected for the EVA IR Camera. Rather these environments represent the most severe thermal environments located anywhere within the immediate vicinity of the ISS and the docked orbiter for the thermo-optical properties of the camera system. In comparing figure 2 and figure 3, it is obvious that the integrated heat load to the system is much higher for the hot case as compared to the cold case.

The goal for the design of the thermal control subsystem for the camera housing and RCU was to create a robust subsystem so that the camera could be used with minimal operational requirements for the astronaut. A detailed, transient, finite element model (FEM) was created for both the CBU and RCU. In order to accomplish the goal of a robust design, several conservative assumptions were included in the thermal model. For the operational hot case, the CBU and RCU were chosen to be oriented so that the total, absorbed, environmental heat load was maximized. Another conservative assumption in the thermal model is the idea that the camera system operates continuously for a period of 8 hours. The planned EVA time for the IR camera will be much less than 8 hours. The thermal analysis for the CBU showed that the maximum surface temperature reached $53.7^{\circ} \mathrm{C}$ during its operational mode as shown in figure 4 . In an effort to determine the thermal resistance between the camera housing and the electronic components, several thermal vacuum tests were performed. These tests showed the maximum temperature difference between the components and the surface to be approximately $9^{\circ} \mathrm{C}$. Therefore, the electronic components reach a temperature of approximately $63^{\circ} \mathrm{C}$ during the hot case operational scenario described herein, which is lower than the manufacturer's recommended temperature limit of $70^{\circ} \mathrm{C}$. In much the same way, an extreme cold case operational scenario was considered for the CBU and the RCU. However, in the reverse way as before, conservatism was added to the analysis by orienting the components so that the total absorbed energy was minimized throughout the EVA. Figure 4 shows the temperature response of the CBU during the cold case operational scenario. This figure shows that the minimum temperature attained by the CBU was $-5.4^{\circ} \mathrm{C}$. The critical temperature is not of the camera housing, it is the internal electronic components. As before, it was necessary to add the nine degree temperature difference to obtain a minimum component temperature of approximately $4^{\circ} \mathrm{C}$. The minimum published operational temperature for the electronics is $0^{\circ} \mathrm{C}$.

In addition the detailed thermal analysis described above for the camera housing, a very similar analysis was completed for the RCU. The same conservative assumptions were used in the initial analysis of the RCU. The conductive path from the electronic components to the housing was much more effective for the RCU as compared with the camera housing. The same thermal vacuum tests discussed above showed that the electronic components internal to the RCU ran approximately $2^{\circ} \mathrm{C}$ hotter than the aluminum housing. The first analysis for RCU hot case showed that the temperature of the electronic components internal to the RCU exceeds their maximum operating limit after approximately 1.5 hours of continuous use and exposure to the extreme hot case environment described above. The first analysis was refined to remove some of the conservatism and obtain a more accurate solution. The idea that the RCU would be oriented in a manner so that the total environmental flux absorbed by the camera is maximized for the entire duration of an 8-hour EVA is obviously overly conservative. Therefore, another analysis was performed taking advantage of the fact that it is known in advance that the astronaut will be using the RCU with the sun 
located behind him and the RCU situated in front of him. A second, more realistic, analysis was completed assuming that the crewmember would shadow the RCU face from the solar loading due to the sun. The results from this analysis show that the RCU surface temperature reaches $54.8^{\circ} \mathrm{C}$ after 8 hours of continuous operational use. The temperature response of the RCU is shown in figure 5 . Adding $2^{\circ} \mathrm{C}$ to the case temperature shows that the internal electronic components reach approximately $57^{\circ} \mathrm{C}$ during the EVA. As stated above, the maximum use temperature of these electronic components is $70^{\circ}$, well above the maximum predicted temperature. The temperature response for the cold case analysis of the RCU is also shown in figure 5. As shown in this figure, the minimum temperature for the RCU housing was calculated to be approximately $11^{\circ} \mathrm{C}$. The minimum predicted temperature for the electronic components internal to the RCU during operational use was $13^{\circ} \mathrm{C}$, which is well above the minimum published limit of $0^{\circ} \mathrm{C}$.

In addition to the thermal analysis, the camera units were put through a rigorous environmental test program which included an acceptance thermal vacuum test, a qualification thermal vacuum test, and an extensive burn-in test.

There were two primary reasons for performing the thermal vacuum tests. The first of these reasons is to cycle the cameras to ensure that the EVA IR Camera and the associated electronic components operated when exposed to the on-orbit temperature extremes. The other reason for performing the thermal vacuum test was to verify the thermal model used to calculate the temperature response of the IR Camera system. All of the temperature limits for the thermal vacuum tests were derived from the analysis results described above. The acceptance thermal vacuum test was completed for all of the flight units prior to delivery as well as the qualification unit. Thermal vacuum requirements state that the acceptance thermal vacuum levels should be equal to the maximum and minimum predicted temperature provided that the temperature difference between the hot and cold case extremes is a minimum of $55^{\circ} \mathrm{C}$.

The predicted temperature difference between the hot and cold case extremes for the CBU was approximately $59^{\circ} \mathrm{C}$. The calculated temperature difference for the RCU was only $44^{\circ} \mathrm{C}$, so the acceptance thermal vacuum levels had to be modified to accomplish the $55^{\circ} \mathrm{C}$ temperature change.

For the qualification thermal vacuum test, the limits were substantially increased to account for uncertainty in the thermal analysis calculations. For this test, both the CBU and the RCU unit were tested outside of the manufacturer's published temperature range. Both units operated flawlessly throughout the entire qualification thermal vacuum test.

The burn-in test was completed on all of the flight units as well as the qualification unit. Of course, the burn-in test was performed in a standard pressure environment. The four temperature setpoints were derived using the minimum/maximum operating and non-operating temperature defined by the camera manufacturer. Unlike the temperature limits described for the thermal vacuum test, the driving temperature for the burn-in test was the ambient temperature not the surface temperature of the hardware.

Table 1 summarizes all of the temperature setpoints used in the verification and validation of the EVA IR Camera system.

Table 1. Temperature setpoints used for the environmental testing of the EVA IR Camera.

\begin{tabular}{|l|c|c|c|l|c|c|}
\hline & \multicolumn{2}{|c|}{$\begin{array}{c}\text { Acceptance } \\
\text { Thermal Vacuum }\end{array}$} & \multicolumn{2}{c|}{$\begin{array}{c}\text { Qualification } \\
\text { Thermal Vacuum }\end{array}$} & \multicolumn{2}{c|}{$\begin{array}{c}\text { Burn-In Test } \\
\text { (Air Temperature) }\end{array}$} \\
\hline & $\mathrm{CBU}$ & RCU & $\mathrm{CBU}$ & RCU & Operating & Non-Operating \\
\hline Hot & $54^{\circ} \mathrm{C}$ & $58^{\circ} \mathrm{C}$ & $64^{\circ} \mathrm{C}$ & $68^{\circ} \mathrm{C}$ & $40^{\circ} \mathrm{C}$ & $60^{\circ} \mathrm{C}$ \\
\hline Cold & $-5^{\circ} \mathrm{C}$ & $2^{\circ} \mathrm{C}$ & $-15^{\circ} \mathrm{C}$ & $-8^{\circ} \mathrm{C}$ & $-5^{\circ} \mathrm{C}$ & $-30^{\circ} \mathrm{C}$ \\
\hline
\end{tabular}


figure 4

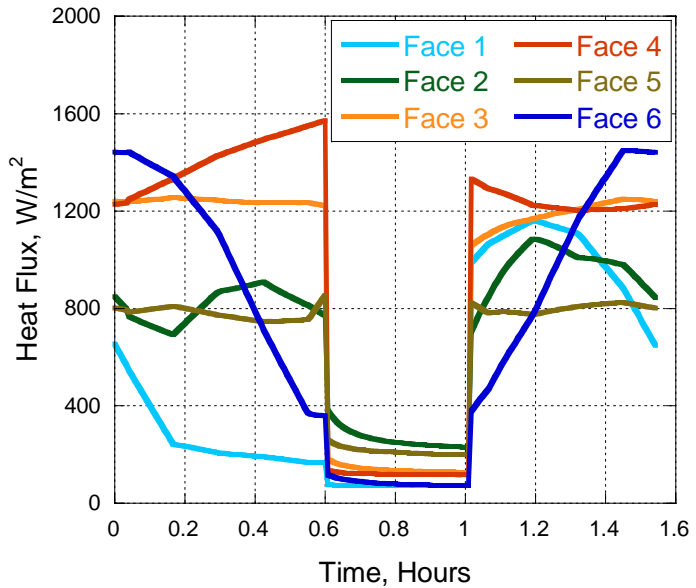

figure 6

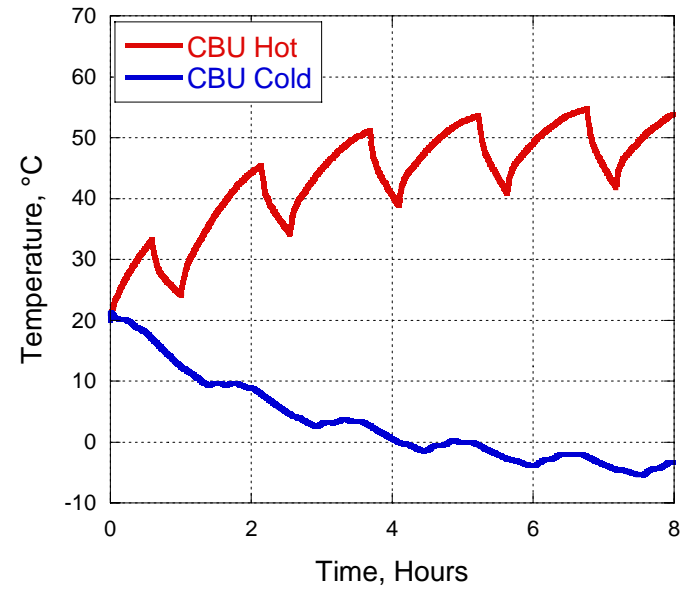

figure 5

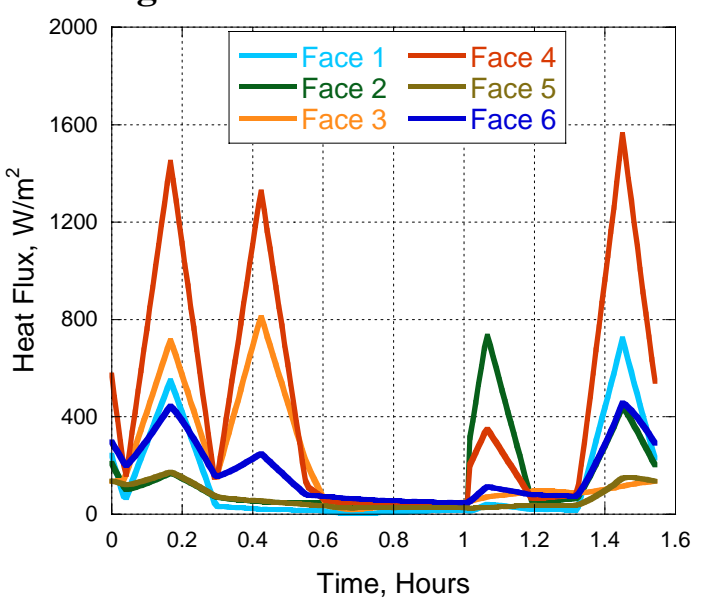

figure 7

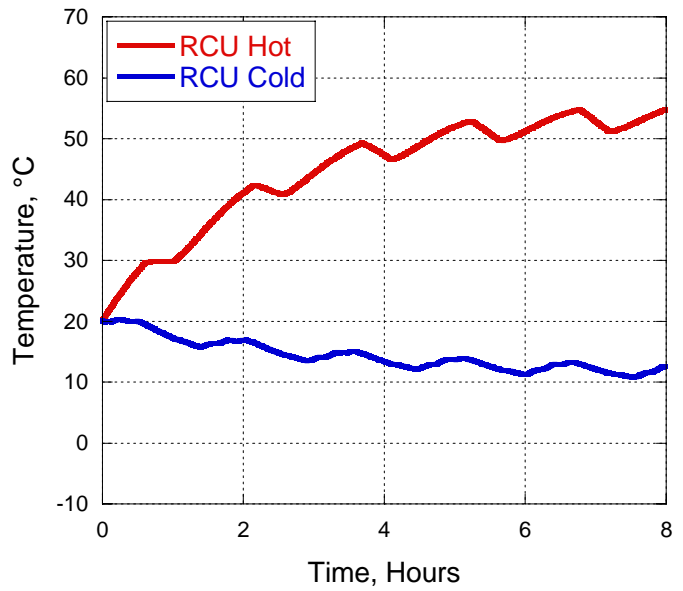

CAMERA OPERATON

Early in the program, the team selected a Model S-65 Infrared Camera manufactured by FLIR Corporation as an off-the-shelf model to modify into a flight unit. FLIR was eager to work with NASA to transform their commercial product into a space flight instrument.

Great emphasis was placed on delivery of a camera that functioned correctly, and was ideally suited to the mission. Camera operation and user interfaces needed to be optimized for use in the harsh environment. User involvement was a key step in this process. The team decided early on to incrementally develop the system using prototypes and engineering units which were continuously evaluated and refined by the user (Astronauts).

\section{BLUE ROOM TEST 1}

After we designed and built the first prototype, we held a 1-G Suited EVA Evaluation, known as a "Blue Room Test". The team built two different brackets to mount the Commercial-Off-The-Shelf (COTS) IR Camera. Three experienced astronauts were recruited to help in the evaluations.

The evaluations consisted of Different Translation Options, Remote Control Cable Length and Cable Management options, Camera Lens Insulation options, Ball Joint mounting of the Camera Body, Camera Body Switches and Switch Guards, Bayonet options, Remote Control Shape, Remote Control Cable, and Shadowing Options.

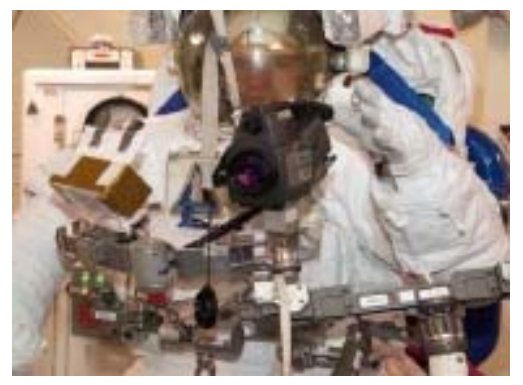
It was clear from the testing that the form factor needed to change significantly. 


\section{TABLE-TOP EVALUATION}

The Table-Top Evaluation is an informal event in which several astronauts get a chance to evaluate a mockup of the new design and suggest ways to improve it. This permits the team to get feedback from a larger group of experienced astronauts. Incorporating this feedback into the design, the team improved the bracket, the designs of the Lens Insulation, Ball Joint, Camera Body Switches, Bayonet, Remote Control and Remote Control Cable.

\section{NEUTRAL BUOYANCY LABORATORY (NBL) TEST}

The NBL is a very large pool with the dimensions of 202 feet x 102 feet x 40 feet deep and holds 6.2 million gallons of water. It contains mockups of the Space Station Modules and the Space Shuttle's cargo bay and Remote Manipulator System (RMS, also known as the Canadian Arm). Astronauts wear extravehicular mobility units (spacesuits) in the water and are made neutrally buoyant to neither rise nor fall in the tank. This reduces the sensation of gravity and provides a very useful simulation for learning firsthand about working in the space environment.

The NBL allowed the astronauts to get a feel for how the modified camera would work in space. It was used to evaluate the different translation options, Remote Control Cable Management and Minimum Cable Length, Ingress Aid Clamp, Bayonet options, and Shadowing Methods. It also provided another chance for astronauts to give feedback and suggest design changes.

\section{BLUE ROOM TEST 2}

For the second Blue Room test, the team had a Camera Mockup that was close to the Flight Configuration. The designs of most components were improved to reflect what was learned in previous evaluations.

The Second Blue Room test evaluated the different Methods for Translation with the camera, different Remote Control Cable options, Lens Insulation options, Camera Button Configurations, Camera Operation, Camera Ball Joints, Camera Body Switches, Camera Body Bracket, the Clockable Bayonet, and options for the shape of the Remote Control Unit. The team also evaluated the possible use of a clamp to mount the camera body to the Ingress Aid and developed initial Shading methods.

The team was now ready to start building flight hardware and begin production firmware development. Firmware modifications include the following:

- Functions/Button remapped as a result of removing Joystick (below).

- Several Functions/Buttons were remapped to increase accessibility to critical capability.

- Enhanced existing functions to improve mission effectiveness.

- $\quad$ Disabled Functions/Menus that were not required.
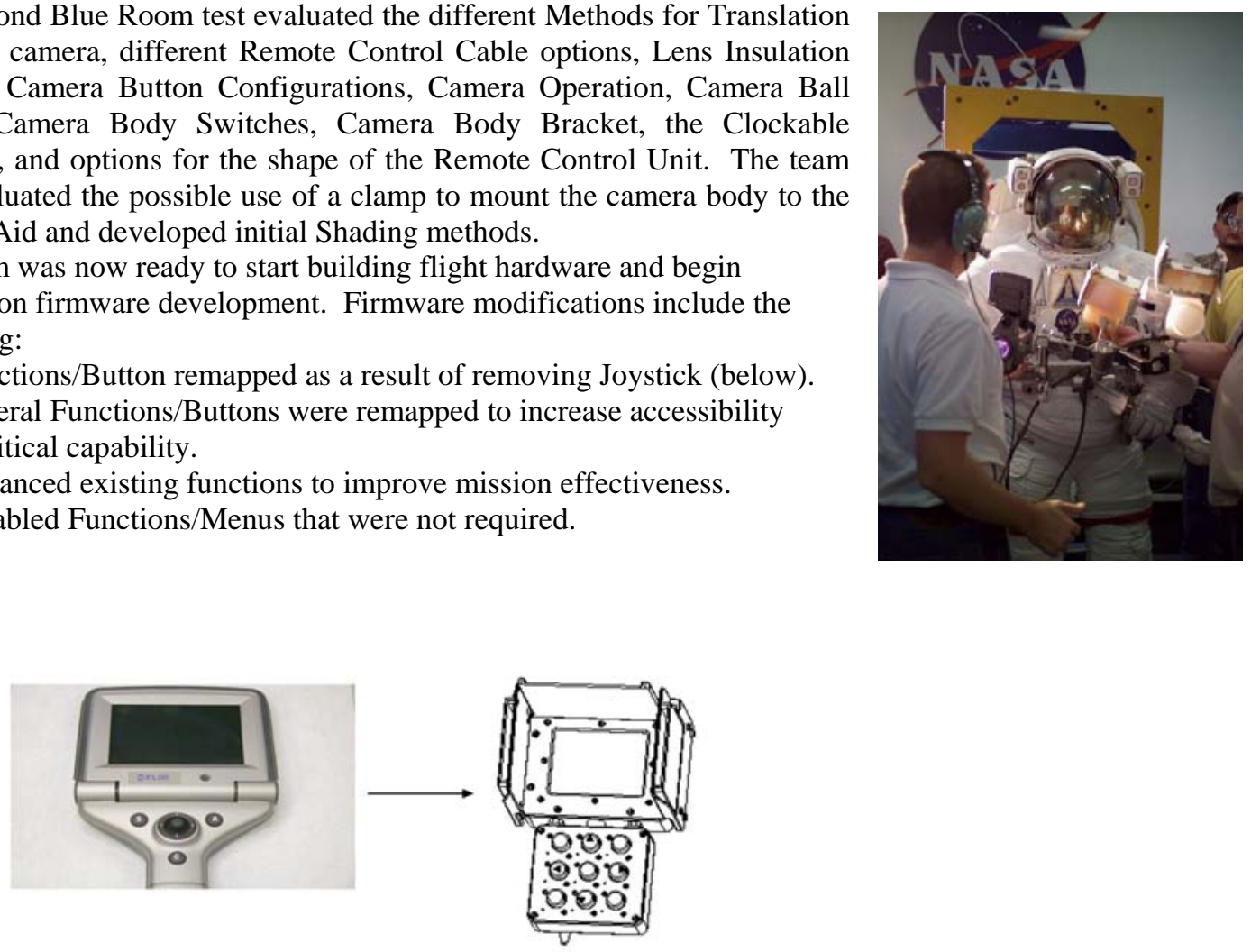


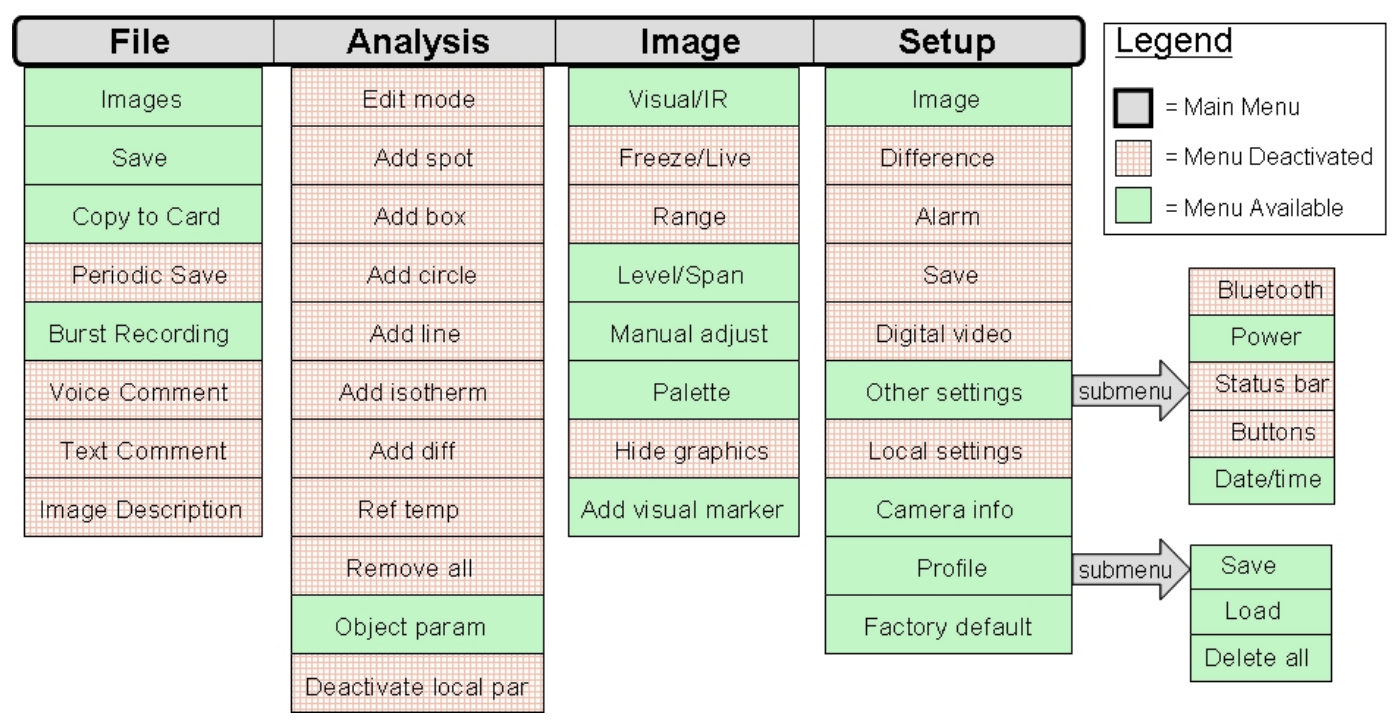

The system menu display (above) was simplified considerably to increase user efficiency. The above figure summarizes the results of this optimization.

Additionally, the firmware was modified to include critical data parameters into recorded sequence files (below). This data would be extremely helpful to the ground processing and performance evaluation of the system.

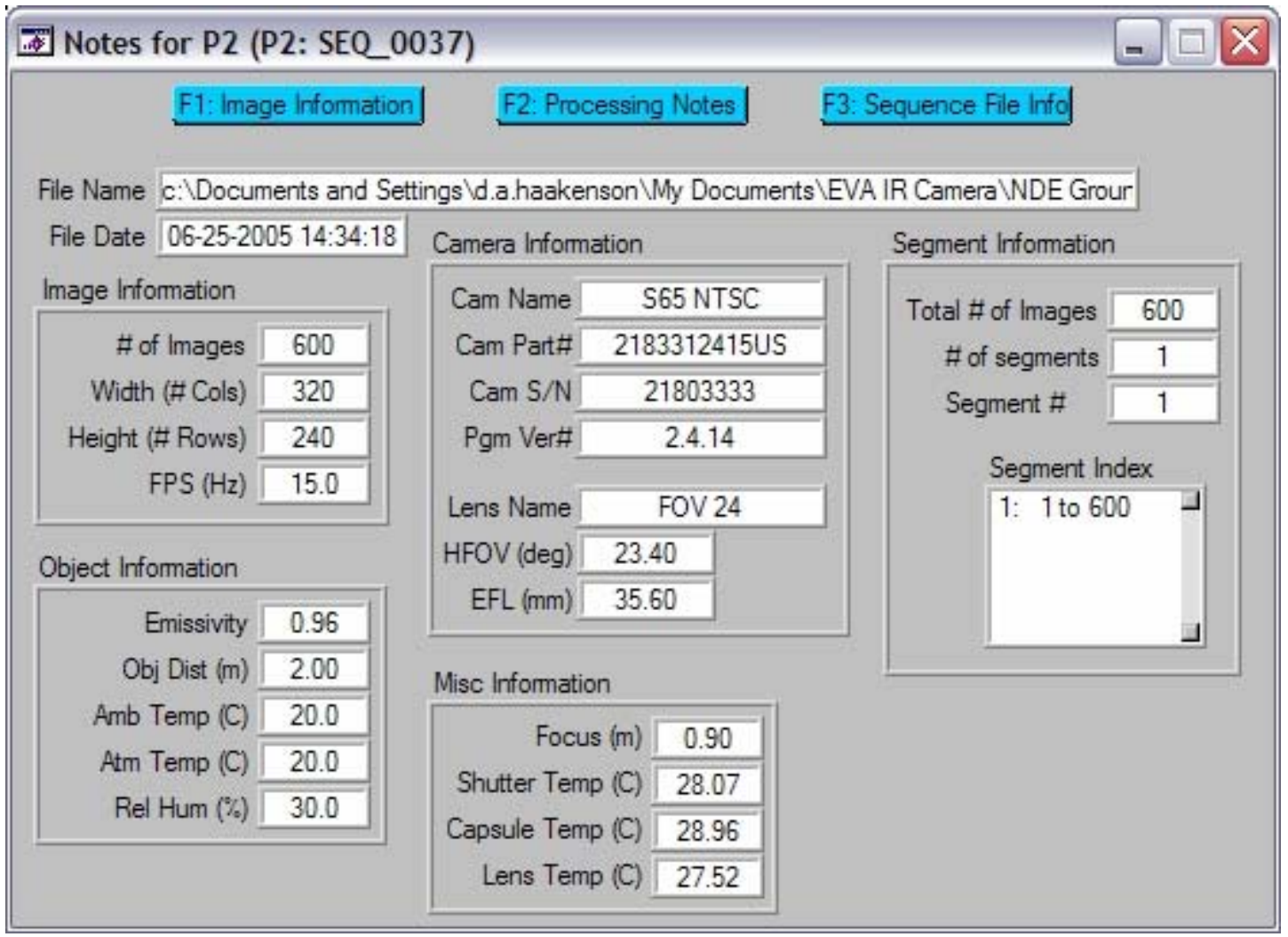



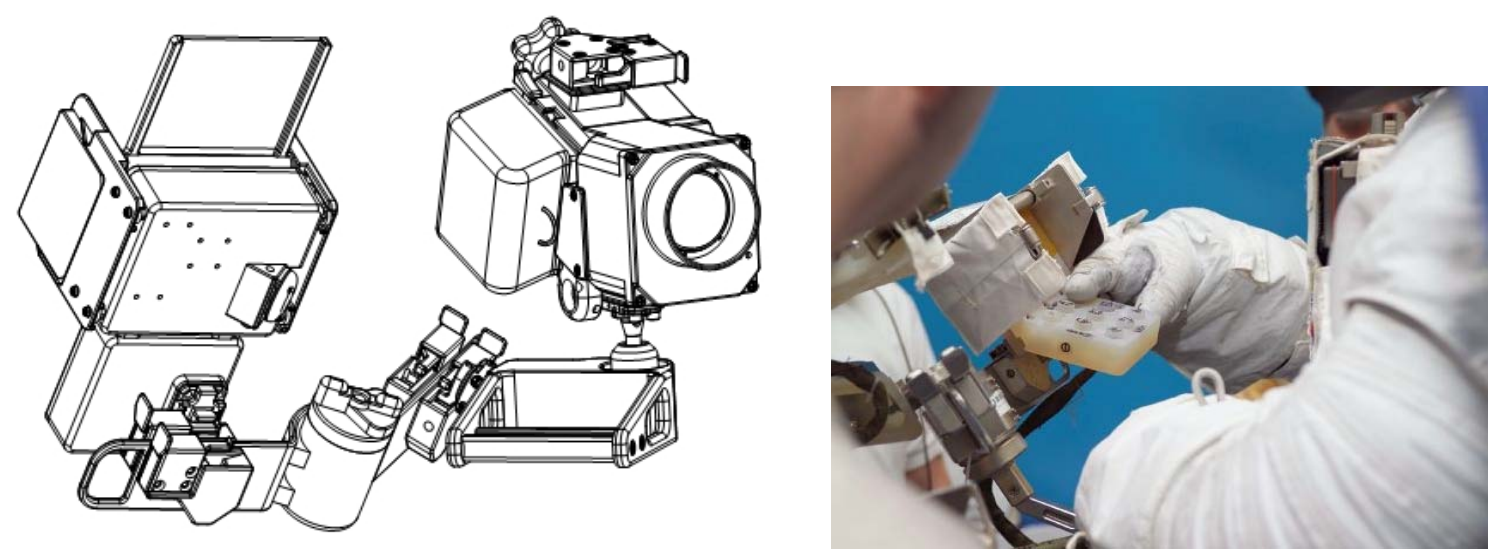

The finished system as delivered to the Johnson Space Center is shown in the picture below.

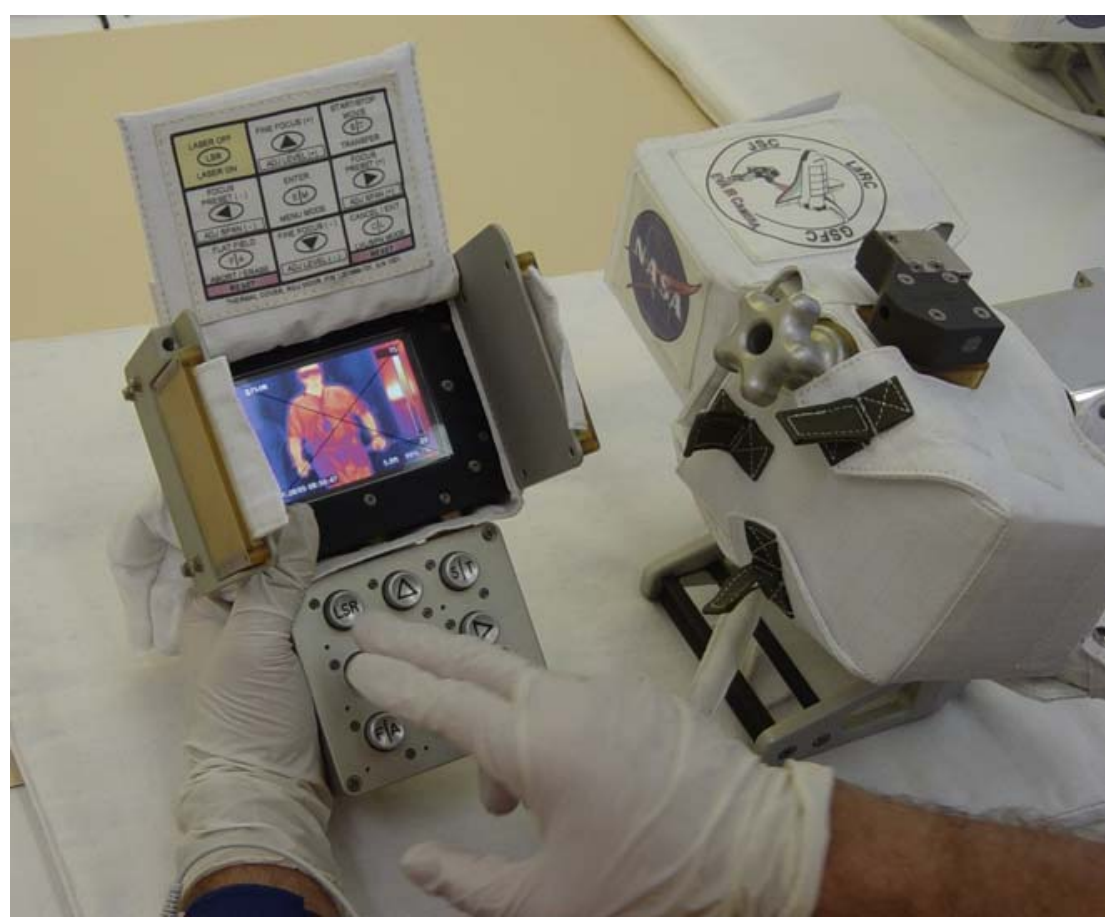

High level of teamwork between the development team and customer (and customer representatives) reduced the chances of major issues at the end of the project. Design and Certification requirements were identified early, and refined often to allow the team to be prepared for the delivery and certification process. A few items surprised the team, but many less than if each party worked in a vacuum.

User representatives (Astronauts) reviewed design prototypes early and often to refine design concepts and correct system problems. A high level of user satisfaction resulted. 